\title{
"Jogo do acesso aberto": desenvolvendo um newsgame para a comunicação e saúde
}

\author{
"Open Access: The Game": developing a newsgame for health \\ communication
}

\section{"Juego del acceso abierto": el desarrollo de un newsgame para la comunicación y salud}

Marcelo Simão de Vasconcellos | vasconcellos@fiocruz.br

Fundação Oswaldo Cruz, Instituto de Comunicação e Informação Científica e Tecnológica em Saúde (Icict), Rio de Janeiro, Brasil.

Flávia Garcia de Carvalho | flaviagc78@gmail.com

Fundação Oswaldo Cruz, Instituto de Comunicação e Informação Científica e Tecnológica em Saúde (Icict), Rio de Janeiro, Brasil.

\section{Juan Puppin Monteiro | flaviagc78@gmail.com}

Fundação Oswaldo Cruz, Instituto de Comunicação e Informação Científica e Tecnológica em Saúde (Icict), Rio de Janeiro, Brasil.

\section{Resumo}

O acesso aberto é importante para a pesquisa científica, mas também tem impacto na saúde. Sua adoção envolve aspectos ideológicos e é necessário conscientizar tanto pesquisadores quanto a população da sua importância. Porém, para o público leigo, a questão do acesso aberto pode parecer pouco tangível. Por isso, é válida a busca de novas abordagens a fim de ilustrar a relevância do acesso aberto e como exatamente ele impacta a vida de todos. A experiência relatada neste artigo envolveu o desenvolvimento de um jogo digital como forma de conscientizar o público da importância do acesso aberto. Apresentamos aqui uma contextualização do tema do jogo, uma discussão sobre o uso de jogos para informação e conscientização, chamados de newsgames, e descrevemos as diversas etapas do desenvolvimento do jogo em questão. Concluímos apontando alguns elementos aprendidos com esse processo.

Palavras-chave: Acesso aberto; Jogo digital; Newsgame; Serious game; Game design; Comunicação e saúde; Jogos de vídeo. 


\begin{abstract}
Open access is important to scientific research, but also has an impact on health. Its adoption involves ideological aspects and it is necessary to educate both researchers and the public about its importance. But for the general public the open access may seem little tangible. So it is valid to search for new approaches to illustrate the relevance of open access and how exactly it impacts on everyone's life. The experiment reported in this article involved the development of a digital game as a means to become the general public aware of the importance of open access. Here we present a contextualization of the game's theme, a discussion about the use of games for information and awareness, called newsgames, and describe the different stages of the development of the game we have created. We conclude describing some elements learned from this process.
\end{abstract}

Keywords: Open access; Digital game; Newsgame; Serious game; Game design; Communication and health; Video games.

\title{
Resumen
}

El acceso abierto es importante para la investigación científica, sino que también tiene un impacto en la salud. Su adopción implica aspectos ideológicos y es necesario enseñar su importancia a los investigadores y el público. Pero para el gran público el tema del acceso abierto puede parecer poco tangible. Por lo tanto, es válida la búsqueda de nuevos enfoques para ilustrar la relevancia del acceso abierto y exactamente cómo impacta la vida de todos. El experimento presentado en este artículo incluyó el desarrollo de un juego digital como una forma de concienciar el público de la importancia del acceso abierto. Aquí presentamos una contextualización del tema del juego, una discusión sobre el uso de los juegos para la información y el conocimiento, llamados newsgames, y describimos las distintas etapas del desarrollo del juego que hemos creado. La conclusión presenta elementos observados en el proceso.

Palabras clave: Acceso abierto; Juego digital; Newsgame; Serious game; Game design; Comunicación y salud; Juegos de video.

Contribuição dos autores: Os autores contribuíram igualmente em todas as etapas do artigo.

Declaração de conflito de interesses: não há conflitos de interesse.

Fontes de financiamento: não houve financiamento externo envolvido.

Apresentação anterior: o objeto deste trabalho foi divulgado anteriormente na matérias "Icict inova mais uma vez e cria newsgame sobre Acesso Aberto" (http://www.icict.fiocruz.br/content/icict-inova-mais-uma-vez-e-cria-newsgame-sobre-acessoaberto) e "Primeiro passo do Icict enquanto centro de produção de jogos como forma de comunicação em saúde" (http://www. icict.fiocruz.br/node/2374), ambas veiculadas no site institucional do Icict. Posteriormente, uma matéria sobre o jogo apareceu em forma impressa na Revista de Manguinhos de dezembro de 2015 (https://agencia.fiocruz.br/dezembro-2015).

Histórico do artigo: Submetido:20.jan.2016 | Aceito: 26.jan.2016 | Publicado: 31.mar.2016

Agradecimentos/Contribuições adicionais: Os autores gostariam de agradecer a Ana Maranhão, Rodrigo Murtinho e ao Proqualis na pessoa de Victor Grabois, por terem colaborado de maneira decisiva para o desenvolvimento do jogo descrito neste artigo. Também agradecem aos músicos Henrique Cardoso e Pedro Pereira pela gentil doação da trilha sonora

Licença CC BY-NC atribuição não comercial. Com essa licença é permitido acessar, baixar (download), copiar, imprimir, compartilhar, reutilizar e distribuir os artigos, desde que para uso não comercial e com a citação da fonte, conferindo os devidos créditos de autoria e menção à Reciis. Nesses casos, nenhuma permissão é necessária por parte dos autores ou dos editores. 


\section{Introdução}

Acesso aberto é um tema muito importante para campo científico contemporâneo e vem sendo debatido em diversos aspectos em todo o mundo. Para muitos pesquisadores, o modelo tradicional de publicação científica, baseado em periódicos de acesso pago, dificultam a propagação das ideias, o livre fluxo de informação e o compartilhamento de trabalho entre pares, em última instância prejudicando o progresso do conhecimento e da ciência ${ }^{1}$.

Outra consequência do modelo tradicional, conforme apontado frequentemente, é a criação de barreiras econômicas para o acesso à informação principalmente nos países com menos recursos, que seriam obrigados a transferir fundos que se destinariam a necessidades prementes, como alimentação e saúde de suas populações, para a aquisição de periódicos estrangeiros na expectativa de desenvolver seu avanço científico. Essa transferência de recursos de países mais pobres para os países mais ricos, onde se encontram diversas editoras, agravaria ainda mais as desigualdades entre as nações².

Como alternativa, o acesso aberto, compreendido como literatura online sem custos e sem restrições artificiais como copyright, licenças de uso e similares representa uma abordagem desenhada para remover barreiras entre diferentes grupos e nações ${ }^{3}$. Ele é defendido como forma de promover o livre fluxo de informações, a livre associação entre pares e a exposição de ideias a um debate mais amplo possibilitando, ao mesmo tempo, que pesquisadores nos países mais pobres tenham acesso a informações de qualidade. Assim, governos e outras instituições de fomento científico poderiam direcionar seus recursos para outras necessidades de pesquisa em vez de consumi-los na compra de periódicos ${ }^{4}$.

No que tange ao acesso à informação, o acesso aberto tem influência direta na saúde. Conhecimento atualizado sobre as últimas descobertas no campo da saúde pode contribuir de forma decisiva para a melhora da saúde tanto de pacientes individuais quanto da sociedade como um todo. Isto ficou patente nos eventos ocorridos quando da última epidemia de ebola na Libéria. Na ocasião, a confirmação de que se tratava de uma epidemia de ebola foi atrasada pela crença comum de que o vírus não estaria presente naquela parte da África. Essa demora inicial para confirmar a doença pode ter levado à perda de centenas de vidas. Mais tarde se constatou que havia diversos estudos comprovando casos de ebola anteriores na Libéria, porém os artigos estavam em periódicos de acesso privado, inacessíveis aos cidadãos daquele país, chegando a custar metade do salário semanal de um médico 5 . Se estivessem em acesso aberto, haveria uma chance maior de tal conhecimento chegar às pessoas que mais precisavam dele naquele momento. Este é um exemplo trágico, mas emblemático de que acesso aberto tem impacto direto na saúde de indivíduos e populações, justificando-se, portanto, as várias iniciativas para ampliar seu alcance.

O acesso aberto amplo pode ser uma transformação revolucionária na forma de comunicação científica e, como toda mudança de tal magnitude, traz grandes desafios ${ }^{6}$. A adoção do acesso aberto é também um passo ideológico, e um aspecto importante para que a mesma ocorra é conscientizar tanto pesquisadores quanto a população do que está em jogo. Se para pesquisadores em geral, as diferenças entre os dois modelos são bem claras, para o público, a questão do acesso aberto versus acesso privado pode parecer pouco tangível. Não tendo que lidar com a busca de informações científicas validadas, a população poderia simplesmente relegar essa questão como algo que interesse apenas aos pesquisadores. Entretanto, dada a importância do tema, é crucial que também o público se inteire da importância do assunto. Por isso, é válida a busca de novas abordagens a fim de ilustrar para o leigo a relevância do acesso aberto e como exatamente ele impacta a vida de todos. Nossa proposta, relatada neste artigo, envolveu o desenvolvimento de um jogo digital como forma de conscientização do público sobre a importância do acesso aberto.

Nossa iniciativa de criar um jogo que falasse sobre o acesso aberto nasce um ano depois da publicação da Política de Acesso Aberto ao Conhecimento da Fundação Oswaldo Cruz7 . Essa foi instituída como mais uma iniciativa para a promoção do movimento global do acesso aberto ao conhecimento, considerando 
que a informação deve ser um bem público porque é também um dos determinantes sociais de saúde. A criação de um jogo que tem o acesso aberto como tema teve como objetivo experimentar uma nova forma de comunicação e divulgação desse movimento e enfatizar a sua relação com a saúde, de uma maneira mais lúdica e bem-humorada.

\section{Jogos digitais}

Desde o seu nascimento, há mais de quarenta anos, os jogos digitais têm se desenvolvido de forma acelerada e ganhado um público significativo na mesma proporção. Apesar de ser uma mídia ainda relativamente jovem, já em 2007 o faturamento dos jogos digitais ultrapassou o da indústria cinematográfica ${ }^{8}$. Em 2011, o Brasil já contava com o 35 milhões de jogadores ${ }^{9}$ e uma pesquisa do Comitê Gestor da Internet no Brasil apontou que $90 \%$ das crianças tinha seu primeiro contato com as tecnologias de informação e comunicação (TIC) por meio de jogos digitais ${ }^{10}$.

Apesar de associados a crianças e adolescentes, há anos jogos digitais são produzidos e vendidos também para o público adulto. Na verdade, todas as faixas etárias, em maior ou menor grau, fazem uso de jogos digitais. Esse poder de atração dos jogos digitais levou ao surgimento de várias iniciativas de utilizálos como meio de instrução e comunicação. Esse movimento originou os chamados jogos sérios (serious games), um termo de definição ainda debatida, mas que pode ser definido como jogos criados para abordar questões relevantes para a sociedade e gerar algum tipo de consequência na vida real ${ }^{11}$. Um serious game geralmente tem o objetivo de educar, instruir, informar, treinar, conscientizar ou divulgar algum tema, informação ou causa, englobando jogos com fins didáticos, sociais, políticos e artísticos. Três elementos essenciais de um serious game seriam a sua concepção para um propósito específico, a abordagem de temas importantes (ou "sérios") e o fim último de "transbordar" efeitos para o mundo real, que podem variar desde o conhecimento sobre um tema (no caso de um jogo didático) até uma mudança de posicionamento político (no caso de jogos de conscientização social).

Um caso particular dos serious games que tem sido usado cada vez com mais frequência são os newsgames, assim chamados porque são jogos digitais utilizados como forma de divulgação, especialmente usados em sites noticiosos. Bogost, Ferrari e Schweizer ${ }^{12}$ consideram newsgames como um tipo de obra realizada na articulação entre jogos digitais e jornalismo. Tais jogos teriam o papel de demonstrar em forma de processo, por meio da interação do usuário com suas regras e mecânicas de funcionamento, os aspectos de uma determinada notícia ou assunto. Nesses contextos, o uso do jogo seria particularmente adequado para demonstrar aspectos funcionais dinâmicos do tema em questão. Por exemplo, um jogo comentando uma atual queda do euro poderia colocar o jogador no papel de um investidor no mercado financeiro, experimentando de forma interativa as diversas engrenagens econômicas e sociais que regem o câmbio internacional.

Dentro dessa classificação mais ampla, haveria diversos tipos de newsgames, tanto em termos de forma quanto de abordagem temática. Assim, entre outros, existiriam newsgames editoriais que seriam o equivalente a um editorial de jornal, newsgames infográficos, fundamentalmente baseados em imagem, dando dinamismo e interação aos tradicionais infográficos informativos, newsgames documentais equivalentes a documentários em formato lúdico e newsgames comunitários, criados para públicos locais, geralmente incorporando partes do jogo também no mundo real e não apenas diante da tela ${ }^{12}$.

Por sua vez, Sicart ${ }^{13}$ adota uma definição mais restrita, defendendo que newsgames são jogos projetados com o objetivo de ilustrar um evento ou assunto particular através de suas regras e mecânicas, visando participação no debate público. Assim, ele localiza newsgames não apenas como um subtipo dos serious games, mas como um subtipo de jogos políticos. Segundo a sua concepção, newsgames são necessariamente específicos, atrelados a eventos atuais, localizados de modo granular no tempo. Nesse sentido, newsgames não aspiram a uma permanência, mas são tão momentâneos quanto as notícias que comentam ou ilustram. 
Por outro lado, ao contrário de Bogost, Ferrari e Schweizer ${ }^{12}$, Sicart não atrela necessariamente newsgames ao jornalismo estabelecido, tornando o debate público sua característica essencial ${ }^{13}$.

Embora as duas abordagens tenham suas diferenças, existem elementos que convergem entre si, tornando possível apontar algumas características fundamentais dos newsgames. Em termos de conteúdo eles tendem a abordar temas contemporâneos, seguindo assim a lógica do jornalismo ao qual se associam ${ }^{12}$. Em termos de forma, os newsgames tendem a ser mais diretos que jogos convencionais, justamente por serem mais momentâneos como as notícias, não podendo contar com uma presença assídua de jogadores. Por isso, em geral têm regras mais simplificadas, passíveis de serem aprendidas rapidamente por um usuário casual. Em termos de uso, os newsgames funcionam tanto como um "chamariz", apresentando certo tema ao usuário e guiando-o para um conteúdo mais aprofundado, geralmente em forma textual, quanto são estruturas complementares ao texto escrito, aparecendo como equivalentes interativos a um infográfico ou quadro informativo em uma matéria escrita. Por fim, eles pressupõem participação do usuário, seja conforme apontado por Sicart ${ }^{13}$, abrindo espaço e fomentando o debate público, seja simplesmente dando ao jogador a oportunidade de controlar em algum grau a experiência informativa.

Dadas essas características apresentadas, foi possível confirmar que o tipo de material de divulgação que se pretendia desenvolver seria mais adequado no formato de um newsgame e esta constatação orientou o desenvolvimento do projeto.

\section{Objetivos do jogo}

Usamos o formato de newsgame para criar um material de comunicação inovador, um jogo que fosse atraente e divertido, mas ao mesmo tempo que apresentasse uma questão relevante para o público, oferecendo um caminho para obter mais informação. Como os serious games em geral e os newsgames em particular, tal jogo não teria um fim em si mesmo como entretenimento, mas tentaria promover consequências para o mundo real, no caso, uma conscientização sobre o acesso aberto, além de despertar o interesse do usuário em saber mais sobre o assunto.

Nossa preocupação também foi de conceber um jogo levando em consideração as especificidades próprias de produção de sentidos de um jogo, evitando sobrecarregá-lo com textos explicativos preestabelecidos, mas deixando que os sentidos emergissem do processo de jogar, ou seja, da interação do usuário com as regras e mecânicas do jogo. Com esses objetivos, desenvolvemos um jogo digital relativamente simples e curto, mas que proporciona uma experiência lúdica para o público: o “Jogo do acesso aberto”.

Quanto a esse público, uma vez que o planejado seria hospedar o jogo no site institucional do Instituto de Comunicação e Informação Científica e Tecnológica em Saúde (Icict) da Fundação Oswaldo Cruz, não havia uma caracterização específica. Por esta razão, estabeleceu-se que deveria ser um jogo de curta duração, que não exigisse um grande engajamento por parte do jogador. Para tanto, optamos por um jogo que pudesse funcionar em qualquer navegador de internet, sem solicitar a instalação em computadores pessoais e que não exigisse requisitos de sistema avançados nesses computadores. Para facilitar ao máximo o acesso, suas dimensões foram restritas a 615 x 400 pixels, o que permite que se integre adequadamente a uma página do site do Icict. O nível de dificuldade foi planejado para não exigir que os possíveis jogadores já tivessem experiência com outros jogos, mas para demandar alguma habilidade motora de modo que o jogo não seja monótono. Ele deve também proporcionar algum resultado para o jogador (vitória ou derrota), de modo que funcione como jogo e não como mera atividade interativa. 


\section{Conceituação}

Ao se decidir pela construção de um jogo sobre acesso aberto houve uma consulta a especialistas no assunto a fim de levantarmos quais seriam os argumentos relativos ao tema mais importantes a serem apresentados aos usuários. Em conversa com esses especialistas, entre várias informações proveitosas, nos foi apresentada a matéria previamente mencionada, que relacionava o ebola com a questão do acesso aberto, defendendo que uma adoção mais ampla dessa forma de acesso poderia ter tido um impacto benéfico na luta contra a epidemia desse vírus na Libéria ${ }^{5}$. Inspirados por esse evento, levantamos os elementos dramaticamente mais marcantes: o avanço de uma epidemia, a busca de pesquisas que poderiam auxiliar em uma cura, a barreira à pesquisa criada pelo acesso privado, e o acesso aberto como uma iniciativa para auxiliar a pesquisa científica.

Mesclamos esses elementos em um cenário inicial, imaginando o jogo como uma narrativa em que, em meio a uma epidemia, um pesquisador freneticamente busca informações na forma de artigos científicos que possam auxiliá-lo a descobrir uma cura para a doença. O jogador controla esse pesquisador, andando por uma cidade não especificada e indo a várias instituições espalhadas pelo cenário em busca de artigos científicos. Enquanto algumas instituições lhe negam acesso às informações, pois os artigos estão em acesso privado, outras adotam o modelo de acesso aberto e lhe dão os artigos que auxiliam na descoberta da cura.

Logo de início, foi descartada a ideia de associar a epidemia ao ebola, pois nos pareceu que mostrar uma narrativa tão sombria poderia afastar jogadores. Por isso, a epidemia ficou indefinida e, no jogo, não se menciona as pessoas que estariam doentes. Pelo mesmo motivo, pensou-se em um estilo de representação não realista, mas caricato e divertido, de forma a cativar o jogador, e tal diretriz orientou o projeto visual do jogo.

\section{Projeto visual}

O desenvolvimento do projeto visual foi iniciado com uma pesquisa da cultura visual relacionada ao acesso aberto e de outras obras às quais o jogo poderia se aproximar, como outros jogos digitais e animações, que conferem um certo caráter intertextual para o trabalho, que poderia induzir o público a reconhecer a nova produção como parte do conjunto geral dessas obras. A partir dessa pesquisa, produzimos desenhos cujo conjunto formou a arte conceitual do projeto, definindo o estilo visual, como paleta de cores, objetos do mundo do jogo e desenhos e expressões dos personagens.

Assim, optou-se por um visual de cores claras e vivas, um estilo próximo ao de desenhos animados. A paleta de cores deu destaque aos matizes de laranja, muito frequentes no material de divulgação do movimento global pelo acesso aberto. As demais cores que compuseram a paleta foram selecionadas para harmonizar com esses matizes de laranja, que foram aplicados no cenário do jogo, e para fazer contraste de matiz e valor, como no caso dos objetos e metáforas visuais representando os periódicos pagos e o avanço da epidemia.

O personagem foi desenvolvido para ser cômico e expressivo dentro do espaço limitado de 64 por 64 pixels, que foi um requisito para o desenvolvimento do jogo. Assim, seu desenho enfatizou a proporção da cabeça, para dar destaque aos olhos, enquanto o corpo recebeu tronco e membros pequenos para simplificar o trabalho de animação de personagem. Apesar de representar um pesquisador, o personagem não foi apresentado com um jaleco, mas com trajes comuns, de modo a ampliar a identificação com o usuário leigo, adequando-se assim ao propósito do jogo de mostrar que o acesso aberto é um assunto relevante para todos (Figura 1). 


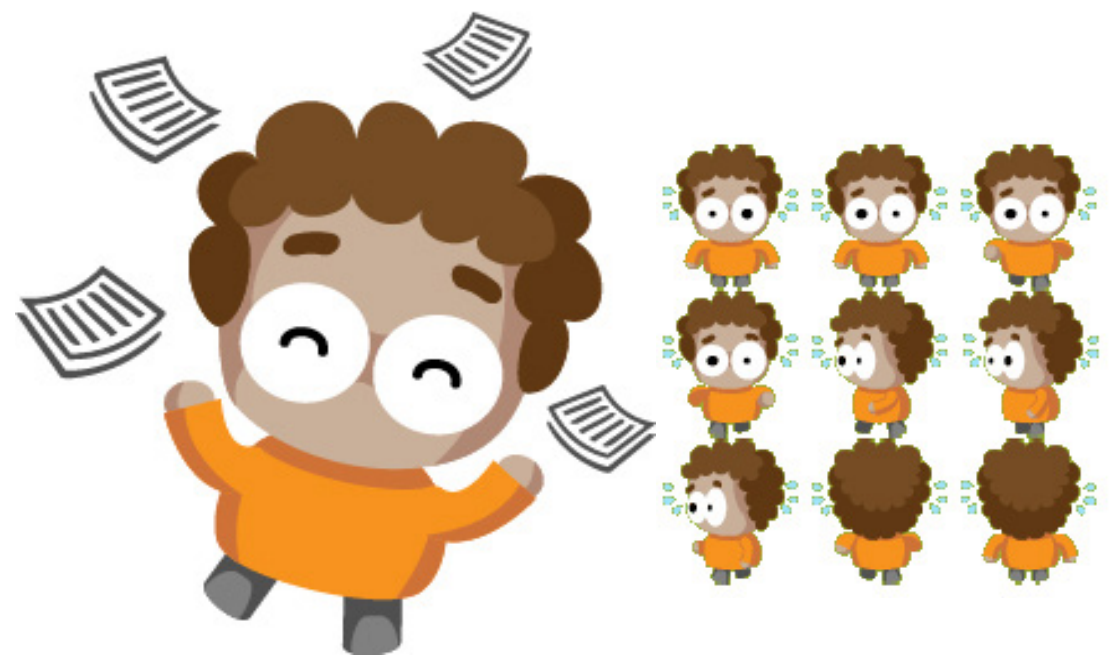

Figura 1 - Desenho do personagem do jogo Fonte: Elaborada pelos autores deste artigo.

\section{Regras}

Uma parte crucial de qualquer jogo digital é seu sistema de regras, que determina, além das condições de vitória e derrota, as ações disponíveis ao jogador e a forma como as informações do jogo serão representadas na interface. Como era importante que o jogo fosse bem acessível ao público em geral, optou-se por um conjunto de poucas regras simples, mas que se articulam para expressar o sentido desejado para o jogo.

A tela principal mostra parte de uma cidade, com prédios dispostos em fileiras. Embora os prédios e as árvores estejam representados de frente para o usuário, a vista do espaço é de cima. O jogador controla um pesquisador que pode andar para a direita, esquerda, cima e baixo, que no contexto do cenário equivalem a leste, oeste, norte e sul, respectivamente. Existem alguns prédios destacados que representam as instituições de pesquisa que contêm artigos que podem auxiliar a descoberta da cura da epidemia (Figura 2). O jogador deve fazer o pesquisador andar (usando as setas do teclado) até cada instituição e tocar em sua porta. Quando isso ocorre, o pesquisador descobre se a instituição em questão adota o acesso privado ou o aberto. No primeiro caso, surge a imagem estilizada de um cadeado com um cifrão, representando um bloqueio associado à necessidade de pagamento. No segundo, a instituição adota o acesso aberto. Surge o símbolo do acesso aberto sobre o prédio e o pesquisador consegue um dos artigos que precisa.

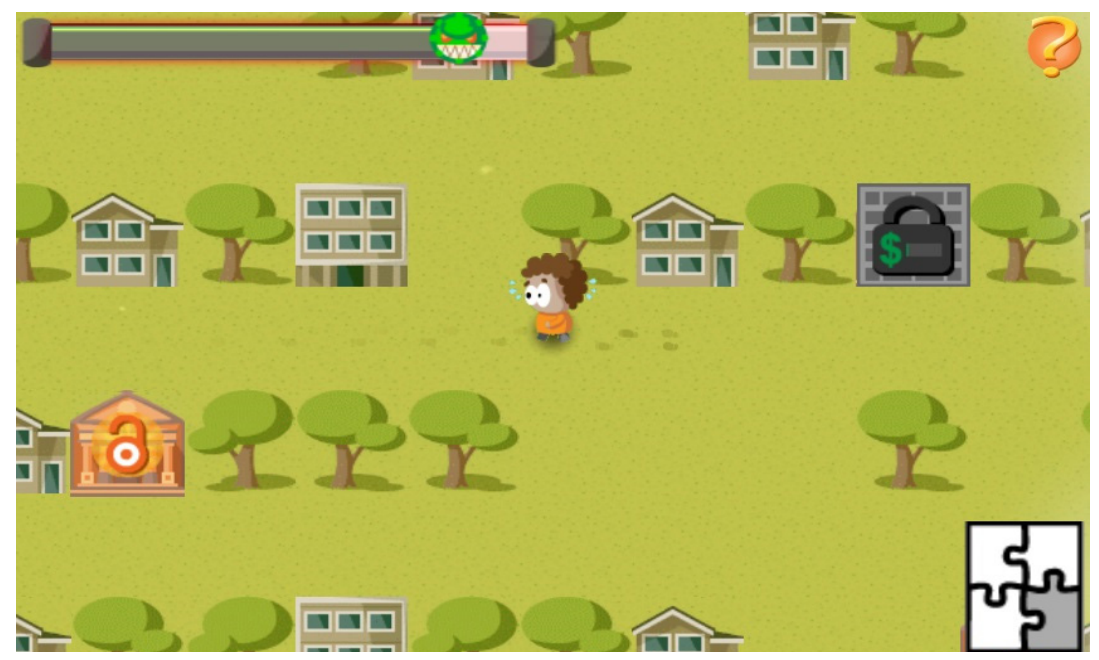

Figura 2 - Tela principal do jogo

Fonte: Elaborada pelos autores deste artigo. 
No canto inferior direito da tela há um quebra-cabeça de quatro peças, representando cada artigo necessário para a descoberta da cura. Ao encontrar um artigo, uma peça é preenchida. Quando as quatro peças estiverem preenchidas, o pesquisador conseguiu resolver o "quebra-cabeça", isto é, encontrar a cura a partir dos artigos encontrados. Apesar da representação simples, procura-se mostrar aqui que cada descoberta científica se baseia em pesquisas prévias e que o acesso a esse corpo de conhecimento anterior é essencial para que novos avanços ocorram.

Como forma de dar um senso de urgência ao jogador, estabeleceu-se um limite de 40 segundos para que ele consiga recuperar os quatro artigos que permitem descobrir a cura. Isso é representado visualmente com uma barra no canto superior esquerdo, com um desenho estilizado de um vírus, simbolizando a epidemia se alastrando. Se a barra se encher completamente, a epidemia não pode mais ser contida e o jogador perde o jogo. É mostrada uma tela descrevendo as consequências da derrota, mas, mesmo assim, é buscado um tom leve e bem-humorado (Figura 3). Nessa tela também aparecem botões para tentar novamente, para os créditos e um link para o jogador saber mais sobre o acesso aberto.

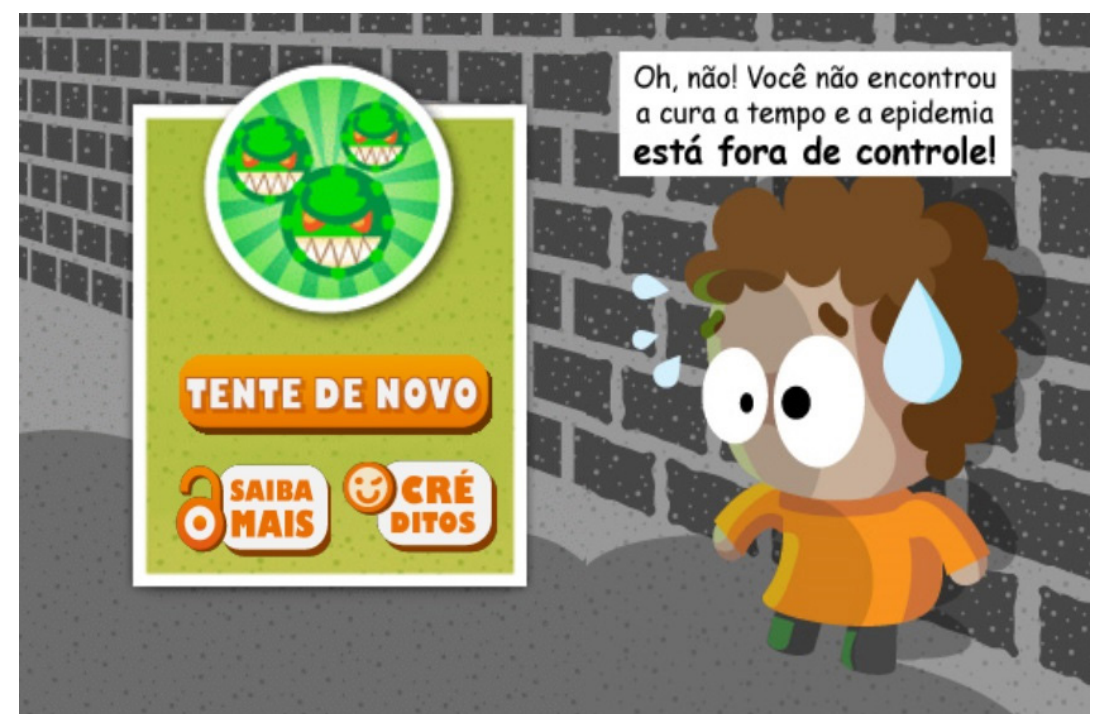

Figura 3 - Tela de derrota

Fonte: Elaborada pelos autores deste artigo.

Embora a posição das instituições de pesquisa no mapa sejam sempre as mesmas, a cada jogo é aleatoriamente definido se uma determinada instituição adota acesso pago ou aberto. Isso é feito para impedir que o jogador memorize a posição de cada instituição que adota acesso aberto. Caso o jogador consiga encontrar os quatro artigos antes do tempo acabar, ele vence o jogo e é mostrada a tela de vitória (Figura 4). Nesta tela também aparecem botões para tentar novamente, para os créditos, e um link para o jogador saber mais sobre $\mathrm{o}$ acesso aberto. 


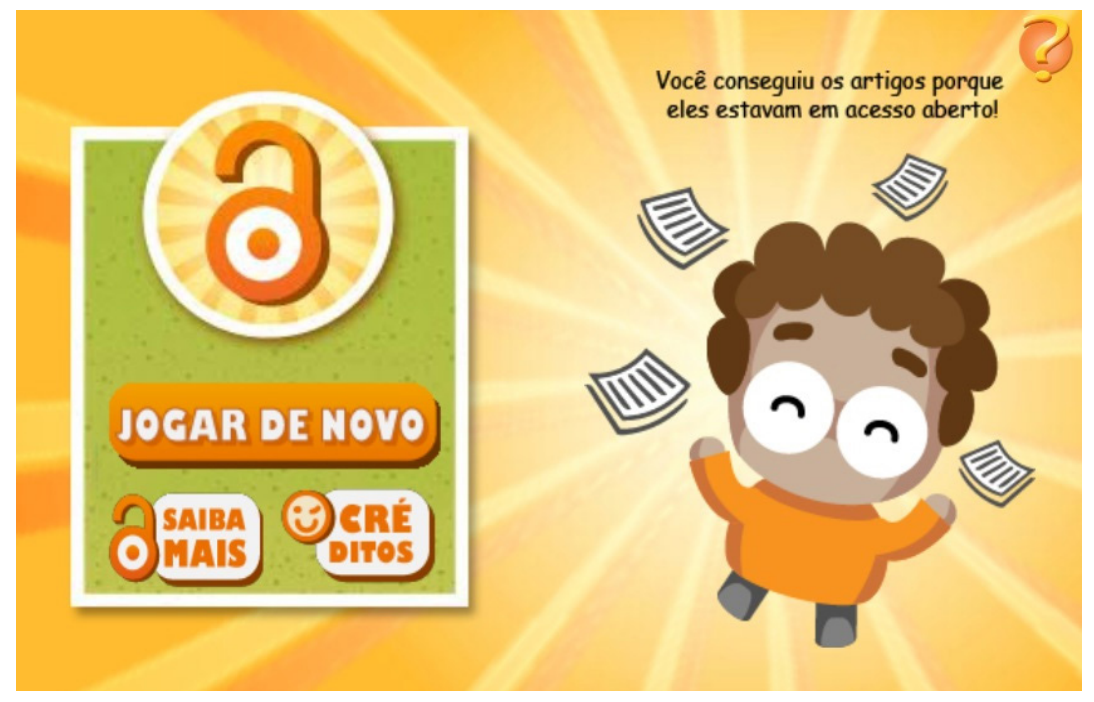

Figura 4 - Tela de vitória

Fonte: Elaborada pelos autores deste artigo.

\section{Desenvolvimento}

De posse das regras definidas e das imagens, o jogo foi desenvolvido em um game engine (um aplicativo que facilita a programação de jogos) apropriado. Para o desenvolvimento do jogo, optou-se por utilizar o Construct 2, um engine de jogos 2D baseado em HTML5. Essa ferramenta permitiu o desenvolvimento do game de forma rápida, mesmo com uma equipe bem reduzida. Além disso, a tecnologia HTML5 oferece compatibilidade com uma ampla gama de dispositivos, o que elimina a necessidade de criar várias versões do mesmo aplicativo.

O engine reúne todos os elementos que formam o jogo (textos, áudio, imagens etc.) e permite a construção das regras através de um formato simplificado de programação. Ao final do processo, ele publica o jogo, isto é, exporta um conjunto de arquivos em um formato já apropriado para ser inserido em um website convencional.

O jogo tem como sua plataforma principal uma página no site do Icict. Nela, constam informações sobre o movimento do acesso aberto, links para as versões em inglês e espanhol do jogo, os créditos do desenvolvimento do projeto e o jogo em si, que é apresentado diretamente na página. Além do HTML5 e a programação visual do Construct 2, foi utilizado Javascript e CSS para implementar funções que o engine não oferecia.

\section{Dificuldades e soluções}

Apesar da aparente linearidade proporcionada pela organização em tópicos deste artigo, a criação do jogo aconteceu com a participação ativa dos integrantes da equipe do início até a conclusão do projeto. Cada teste de protótipo proporcionou oportunidades de aprimoramento do personagem, da sonorização e de aspectos narrativos, que foram acrescentando maior clareza à mensagem que pretendemos transmitir.

O maior desafio na construção do game foi desenvolver uma única versão capaz de funcionar em qualquer navegador, incluindo as versões móveis de cada um. Para alcançar esse objetivo o jogo passou por testes em todos os principais navegadores a cada etapa finalizada. Desse modo, a equipe foi capaz de corrigir os erros apresentados nas plataformas, evitando que esses se acumulassem e se tornassem um problema maior.

Entre os navegadores suportados, o que ofereceu os maiores problemas foi o Safari (produzido pela Apple) e, para corrigi-los, foi preciso adicionar todos os sons e músicas do jogo em um formato próprio 
para a plataforma. Pela mesma razão, também foi decidido remover alguns efeitos gráficos que causavam problemas naquele navegador.

Um exemplo que ilustra bem o tipo de dificuldades técnicas encontradas foi a inclusão do botão "saiba mais”, que tem como função abrir uma nova guia com as informações sobre o movimento pelo acesso aberto. O problema é que por medida de segurança contra invasores, os navegadores não permitem abertura de guias por comandos originados em uma aplicação externa, como era o caso do jogo. Para que esse item funcione corretamente, a solução foi adicionar um segundo botão gerado via javascript posicionado dinamicamente sobre a imagem do botão original "saiba mais", mas formatado por CSS de modo a ficar invisível. Desse modo, o clique do usuário é capturado pelo botão invisível e a função de abrir nova guia é efetuada corretamente sem incorrer nos limites impostos pelos navegadores.

Outra dificuldade imprevista foi a necessidade de ensinar os jogadores como jogar. Embora a princípio se pensasse que a simplicidade do jogo garantisse uma apreensão quase imediata das regras, na prática não foi assim. Alguns dos primeiros usuários a testar o jogo tiveram dificuldade de saber como agir, o que levou à necessidade da criação de uma tela tutorial apresentada no início do jogo, ensinando como controlar o personagem e o que fazer (Figura 5). Este episódio nos confirmou a necessidade de testes recorrentes à medida que se desenvolve um jogo digital, principalmente levando-se em conta a enorme diversidade de usuários com diferentes níveis de conhecimento e experiência que têm acesso ao mesmo via internet.

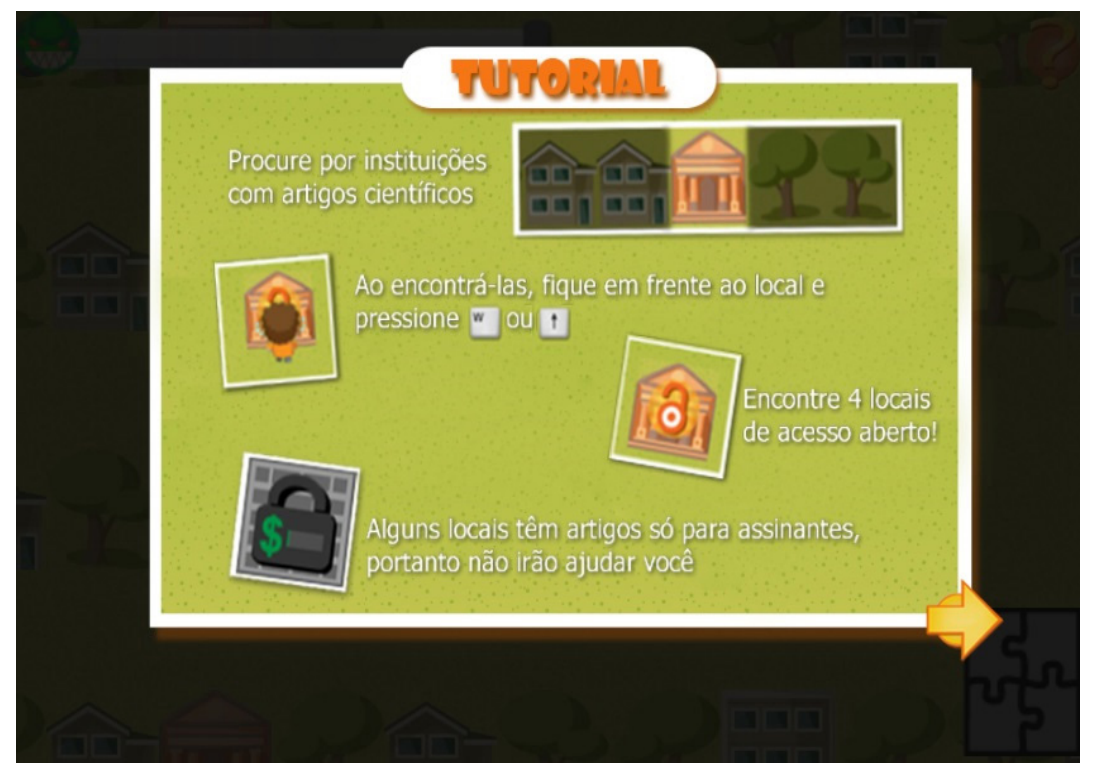

Figura 5 - Tutorial

Fonte: Elaborada pelos autores deste artigo.

Um outro aspecto técnico diz respeito à sonorização do jogo. Embora o primeiro protótipo tenha sido construído usando-se sons gratuitos obtidos na internet, estava claro desde o princípio que essa solução não era adequada. Por outro lado, não se dispunha de verba para contratação de um músico profissional. O problema foi solucionado quando um estúdio especializado em sonorização para jogos digitais tomou conhecimento da iniciativa. Compreendendo a importância do acesso aberto e a necessidade de maior conscientização do público, os dois integrantes do estúdio cederam seu tempo e talentos, produzindo tanto efeitos sonoros quanto músicas originais para o jogo. Embora muitos projetos de jogos digitais releguem a produção de áudio a um segundo plano, ficou evidente nesse processo a importância do uso de áudio profissional como forma de ampliar os efeitos estéticos e afetivos do jogo. 


\section{Recepção}

Uma vez terminado, o jogo foi posto em sua própria página no site do Icict ${ }^{i}$, para acesso do público. A partir de então, o jogo foi divulgado em uma matéria do Icict ${ }^{\mathrm{i}} q u e$ foi replicada em diversos outros sites sobre saúde pública, acesso aberto e divulgação científica. Mais tarde, tal matéria foi reproduzida em formato impresso na Revista de Manguinhos ${ }^{14}$. Junto a isso, o jogo foi divulgado no Facebook e Twitter, onde obteve grande número de compartilhamentos. Por fim, o jogo foi mostrado a um grupo de pesquisadores brasileiros e estrangeiros no XIV Simpósio Brasileiro de Jogos e Entretenimento Digital - SBGames2015, que ocorreu em Teresina, em novembro de 2015.

\section{Considerações finais}

Apesar de ser uma primeira experiência ainda muito modesta em termos de desenvolvimento de jogos digitais no formato de newsgames em favor da saúde, o processo de criação do Jogo do acesso aberto nos permitiu tirar algumas lições importantes, que serão valiosas em projetos futuros.

Em primeiro lugar, o processo de desenvolvimento de jogos para a saúde, exigindo a participação de diversos saberes de diferentes áreas de conhecimento, não é apenas interdisciplinar, mas iterativo. Sua produção não é uma tarefa que pode ser dividida em etapas estanques, como uma linha de montagem, mas há muitas idas e vindas, e por meio delas é que o produto vai sendo refinado até chegar em seu formato final.

Segundo, é crucial não apenas a pesquisa documental, mas o contato com especialistas que vivenciem o tema em questão. A partir de sua experiência e suas percepções, é possível ter uma visão mais orgânica do assunto e eventualmente encontrar os elementos mais estratégicos para serem incorporados ao jogo.

Por fim, a recepção do público e, neste caso específico, dos partidários do acesso aberto, pode ser uma grata surpresa para os desenvolvedores do jogo. Mesmo que, aos olhos da equipe de desenvolvimento tenha sido um jogo propositalmente bem simples, os elogios do público para a iniciativa foram frequentes. Isso foi ainda mais intenso junto aos ativistas do movimento do acesso aberto, que puderam ver um tema tão importante se tornar objeto de um jogo digital acessível ao mundo todo via internet. Através dessa modesta experiência, ficou evidente para nós tanto o potencial que mesmo os jogos digitais mais simples podem ter para promover, divulgar, conscientizar e disseminar temas de saúde quanto o vasto espaço de possibilidades para desenvolvimento de novos jogos em favor da saúde.

\section{Referências}

1. Suber P. Removing the barriers to research: an introduction to open access for librarians. College \& Research Libraries News. 2003(64):92-4.

2. Machado JAS. Difusão do conhecimento e inovação - o acesso aberto a publicações científicas. In: Baumgarten M, editor. Conhecimento e Redes - Sociedade Política e Inovação. Porto Alegre: UFRGS; 2005.

3. Costa S. Abordagens, estratégias e ferramentas para o acesso aberto via periódicos e repositórios institucionais em instituições acadêmicas brasileiras. Liinc em Revista. 2008;4(2):218 - 32.

4. Costa SMDS. Filosofia aberta, modelos de negócios e agências de fomento: elementos essenciais a uma discussão sobre o acesso aberto à informação científica. Ciê da Informação; v 35, n 2 (2006). 2006.

5. Masnick M. Don't Think Open Access Is Important? It Might Have Prevented Much Of The Ebola Outbreak | Techdirt. Techdirt. 2015;2016.

6. Mueller SPM. A comunicação científica e o movimento de acesso livre ao conhecimento. Ciência da Informação; v 35, n 2 (2006); 2006.

7. Política de Acesso Aberto ao Conhecimento. Rio de Janeiro: Fundação Oswaldo Cruz; 2014. 
8. Growth of gaming in 2007 far outpaces movies, music 2008 [citado07jan2010]. Disponível em: http:// arstechnica.com/gaming/news/2008/01/growth-of-gaming-in-2007-far-outpaces-movies-music.ars

9. Gap Closing Between Emerging and Western Game Markets: Newzoo 2011 [cited 2011jun01]. Available from: http://www.newzoo.com/ENG/1504-Detail.html\&id=79

10. Barbosa A, Cappi J, Jereissati T. Pesquisa TIC crianças 2010: pesquisa sobre o uso das tecnologias de informação e comunicação no Brasil São Paulo: CGI.br - Comitê Gestor da Internet no Brasil; 2011 [citado 7 dez 2011]. Disponível em: http://www.cetic.br/usuarios/criancas/2010/apresentacao-ticcriancas-2010.pdf

11. Raessens J. A Taste of life as a refugee: how serious games Frame Refugee Issues. In: Skartveit $H-L$, Goodnow K, editors. Changes in Museum Practice: New Media, Refugees and Participation. New York / Oxford: Berghahn Books; 2010. p. 94-105.

12. Bogost I, Ferrari S, Schweizer B. Newsgames: Journalism at Play. Cambridge: The MIT Press; 2010.

13. Sicart M. Newsgames: theory and design. In: Stevens S, Saldamarco S, editors. Entertainment Computing - ICEC 2008. Lecture Notes in Computer Science. 5309: Springer Berlin Heidelberg; 2009. p. 27-33.

14. Portela G. Jogos Virtuais em Saúde. Revista de Manguinhos. 2015 dez. p.38-39. 